\title{
PERANCANGAN DAN PENGEMBANGAN PROTOTYPE SISTEM PARKIR
}

\author{
Indah Ayu Septriyaningrum¹, Dodon T. Nugrahadi², Ichsan Ridwan ${ }^{3}$ \\ 1,2,3Prodi Ilmu Komputer FMIPA ULM \\ Jl. A. Yani Km 36 Banjarbaru, Kalimantan selatan \\ 1Email : indah.septriya@gmail.com
}

\begin{abstract}
Manual parking systems in mall parking lot services requires a more complex management and development system, not to mention its inefficiency. The information acquired from the parking manager about the the parking space conditions in the field is lacking every day. The purpose of this research is to design and develop a parking system prototype. The development method and system design for this research is the Waterfall method. The results obtained is that this system is able to detect the presence of a vehicle on a designated parking space, with the help of an Intel Galileo Board Gen 2 as the controller, an LDR (Light Dependent Resistor) sensor, and an ultransonic sensor (PING) as an auxiliary. The system is able to display parking activity on a web application, such as empty parking space conditions, occupied parking spaces, time of arrival, parking period, parking space capacity, and also able to display a graphic image of the parking space utilization. It can be concluded that the design and development of the system is successfully implemented.
\end{abstract}

Keyword: Parking system, Intel Galileo Board Gen 2, LDR sensor, ultrasonic sensor

\begin{abstract}
Abstrak
Sistem parkir manual pada pelayanan parkir mall memerlukan pengelolaan dan pengembangan sistem yang lebih rumit dan jauh dari kata efisien. Informasi yang didapatkan pengelola parkir terkait kondisi parkir di lapangan setiap harinya masih kurang. Tujuan dari penelitian ini adalah merancang dan mengembangkan prototype sistem parkir. Metode pengembangan dan perancangan sistem pada penelitian ini adalah metode Waterfall. Hasil yang didapatkan adalah sistem ini dapat mendeteksi keberadaan mobil pada slot parkir yang tersedia dengan bantuan Intel Galileo Board Gen 2 sebagai kontroler, sensor LDR (Light Dependent Resistor) dan sensor ultrasonik (PING) sebagai alat bantu pendeteksi keberadaan mobil. Sistem dapat menampilkan aktifitas parkir pada aplikasi web seperti kondisi lahan parkir kosong, lahan terisi, waktu masuk, waktu keluar, lama parkir dan kapasitas parkir yang tersedia serta grafik pemakaian lahan parkir. Dapat disimpulkan bahwa perancangan dan pengembangan sistem berhasil diimplementasikan.
\end{abstract}

Kata Kunci : Sistem parkir, Intel Galileo Board Gen 2,sensor LDR, sensor ultrasonik 


\section{PENDAHULUAN}

Menurut Imbiri[2], masalah yang ditimbulkan dalam sistem perparkiran adalah kurangnya informasi mengenai lahan parkir yang kosong serta penempatan kendaraan yang tidak sesuai sehingga sering kali pemilik kendaraan membutuhkan waktu yang lama untuk sekedar menemukan tempat parkir yang kosong. Berdasarkan hal tersebut diperlukan sebuah sistem monitoring parkir yang memudahkan pengelola dalam melakukan pemantauan terhadap kondisi lahan parkir.

Dengan kondisi kendaraan roda empat (mobil) yang jumlahnya ratusan bahkan ribuan, membuat pemantauan kondisi lahan parkir dilapangan menjadi semakin tidak praktis dengan menggunakan sistem parkir manual. Saat ini sistem perparkiran dalam suatu gedung sudah mulai menggunakan teknik komputerisasi misalnya pada pelayanan parkir mall, namun pada kenyataannya informasi yang didapatkan pengelola parkir terkait kondisi parkir di lapangan setiap harinya masih kurang.

Seiring dengan fakta-fakta tersebut, penelitian ini dilakukan untuk dapat merancang prototype sistem monitoring parkir sekaligus melakukan pengembangan sistem parkir dengan acuan sistem yang sudah ada sebelumnya. Menurut Laudon [3], prototype adalah versi sistem informasi atau bagian dari sistem yang sudah dapat berfungsi, tetapi dimaksudkan hanya sebagai model awal saja. Dengan begitu nantinya sistem dapat diimplementasikan untuk menangani masalah parkir yang ada, khususnya bagi pengelola parkir yang berkaitan erat dengan layanan parkir. Sehingga pengelola parkir dapat mendapatkan informasi aktifitas parkir yang bermanfaat untuk memonitoring kondisi lahan parkir dilapangan dan pengelolaan informasi yang bisa digunakan dalam pengembangan sistem parkir lebih lanjut.

\section{METODOLOGI PENELITIAN}

Penelitian ini menggunakan metode Waterfall model untuk pengembangan sistem parkir dengan Internet of Things.

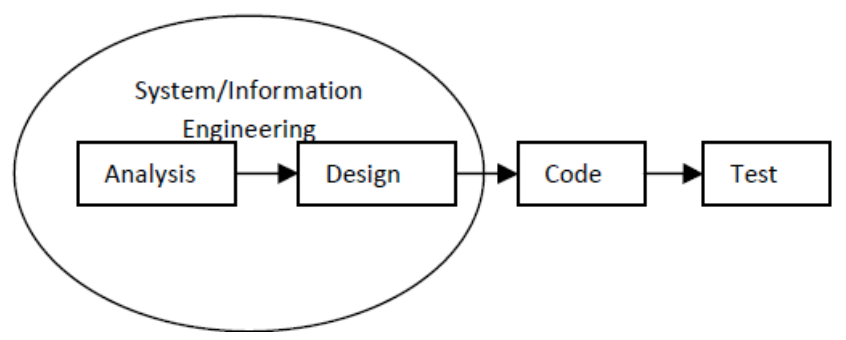

Gambar 1. Model Sekuensial Linear/Waterfall Model[5]

Metodologi yang digunakan dalam penelitian ini mengacu pada model pengembangan Waterfall. Adapun tahapan-tahapan dalam model pengembangan Waterfall yaitu analysis (analisis sistem), design (perancangan), coding/implementation (implementasi), testing (pengujian)[6]. 


\subsection{Analisis}

Tahap analisis merupakan tahapan yang dilakukan setelah melakukan pengumpulan data untuk mengidentifikasi dan mengevaluasi permasalahanpermasalahan, kesempatan-kesempatan, hambatan-hambatan yang terjadi dan kebutuhan-kebutuhan yang diharapkan sehingga dapat diusulkan perbaikannya. Ada beberapa tahap dalam melakukan analisis, yaitu analisis input dan analisis output yang digunakan untuk mengetahui data apa saja yang diperlukan sistem. Serta analisis proses bertujuan untuk menganalisis proses apa saja yang bisa dilakukan oleh aktor terhadap sistem. Pembuatan proses ini dengan menggunakan use case diagram dan activity diagram. Use case yang dibuat yaitu use case melihat informasi parkir, use case melihat laporan, use case memfilter laporan, use case melihat grafik, serta use case memfilter data grafik serta use case mencetak data grafik. Sedangkan activity diagram yang dibuat yaitu proses monitoring kondisi parkir, proses mencetak laporan serta proses mencetak laporan grafik.

\subsection{Gambaran Umum Sistem}

Sistem yang dibangun dalam penelitian ini adalah prototype sistem parkir sebagai media informasi berbentuk aplikasi web. Sistem dapat mendeteksi keberadaan mobil pada slot parkir yang tersedia, sistem dapat menampilkan kondisi lahan kosong jika slot parkir tidak terisi dan dapat menampilkan kondisi lahan terisi jika slot parkir terisi. Sistem juga dilengkapi dengan informasi terkait aktifitas parkir seperti waktu masuk, waktu keluar dan lama parkir. Selain mendeteksi keberadaan mobil sistem juga dapat menghitung kapasitas parkir yang tersedia.

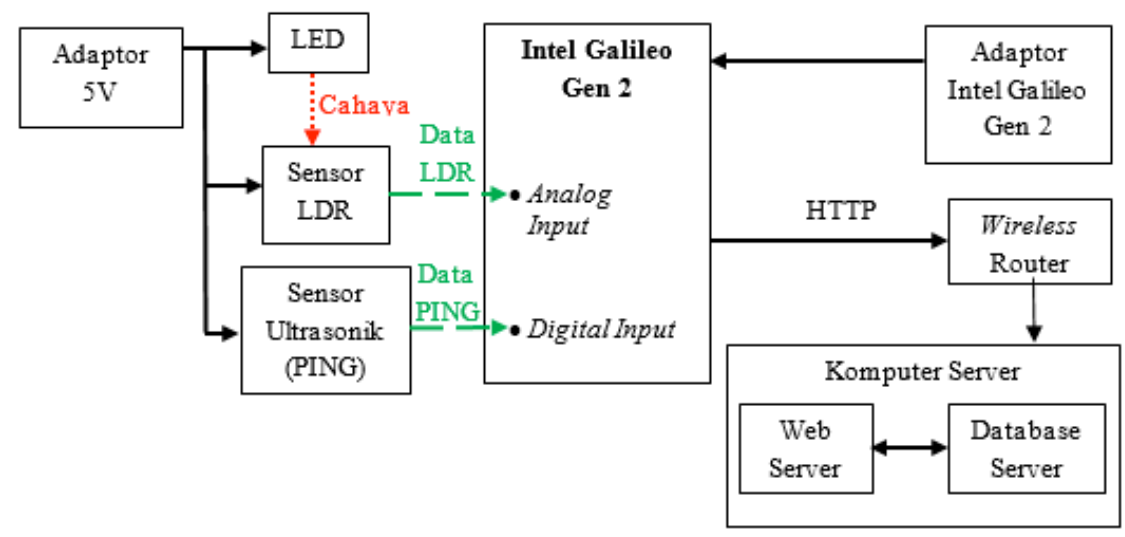

Gambar 2. Blok Diagram Sistem

Sumber : Prototype Sistem Parkir dengan Internet of Things. 2016

\subsection{Analisa Input dan Output}

Setelah pengumpulan data, kemudian dilakukan analisis data yang menjadi masukan, yaitu :

a. Data Analog

Merupakan data yang dikirimkan oleh sensor LDR (Light Dependent Resistor) 


\section{b. Data Digital}

Merupakan daya yang dikirimkan oleh sensor ultrasonik (PING)

c. Data Login

Merupakan data yang digunakan untuk mengetahui kepada siapa saja hak akses web diberikan

\subsection{Perancangan Sistem}

Perancangan akan dilakukan setelah didapat hasil analisis dari sistem yang akan dibuat. Tujuan dari perancangan ini adalah untuk melihat gambaran awal dari sistem, cara kerja sistem, dan antarmuka sistem. Kegiatan yang dilakukan dalam perancangan ini diantaranya yaitu :

a. Perancangan database, yang bertujuan untuk menggambarkan data pada sebuah database

\begin{tabular}{|l|l|}
\hline \multicolumn{2}{|c|}{ t_login } \\
\hline PK & $\underline{\text { id }}$ \\
\hline & $\begin{array}{l}\text { nama } \\
\text { alamat } \\
\text { username } \\
\text { password }\end{array}$ \\
\hline
\end{tabular}

\begin{tabular}{|l|l|}
\hline \multicolumn{2}{|l|}{ t_dataperwaktu } \\
\hline PK & $\underline{\text { id }}$ \\
\hline & time \\
& PING3 \\
& LDR1 \\
& LDR2 \\
& PING2 \\
& PING1 \\
& LDR3 \\
& LDR4 \\
& LDR5 \\
\hline
\end{tabular}

\begin{tabular}{|l|l|}
\hline \multicolumn{2}{|c|}{ t_dataperubahan } \\
\hline PK & id \\
\hline & time \\
& PING3 \\
& LDR1 \\
& LDR2 \\
& PING2 \\
& PING1 \\
& LDR3 \\
& LDR4 \\
& LDR5 \\
\hline
\end{tabular}

Gambar 3. Perancangan Database

Sumber : Prototype Sistem Parkir dengan Internet of Things. 2016

b. Perancangan alat, yang bertujuan untuk menggambarkan rancangan alat yang digunakan dalam pembuatan maket lahan parkir

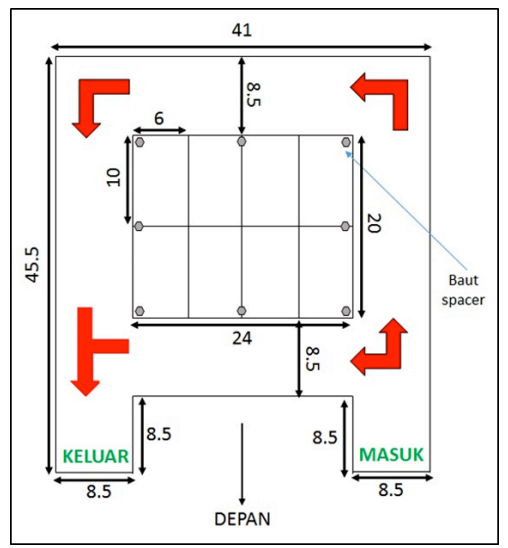

Gambar 4. Perancangan Maket Sistem Parkir (Tampak Atas)

Sumber : Prototype Sistem Parkir dengan Internet of Things. 2016 


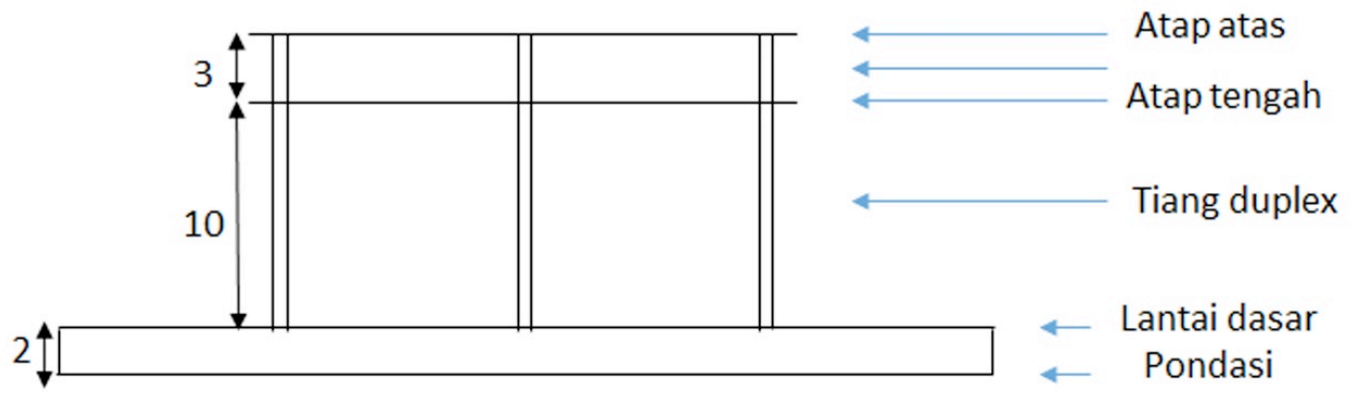

Gambar 5. Perancangan Maket Sistem Parkir (Tampak Bawah)

Sumber : Prototype Sistem Parkir dengan Internet of Things. 2016

c. Perancangan web interface, yang bertujuan agar sistem, program atau aplikasi yang dihasilkan terlihat lebih menarik dan mudah dimengerti pada saat dioperasikan. Halaman login terdapat pada halaman login yang ditujukan untuk admin. Halaman ini bertujuan agar pengguna dapat masuk ke dalam sistem

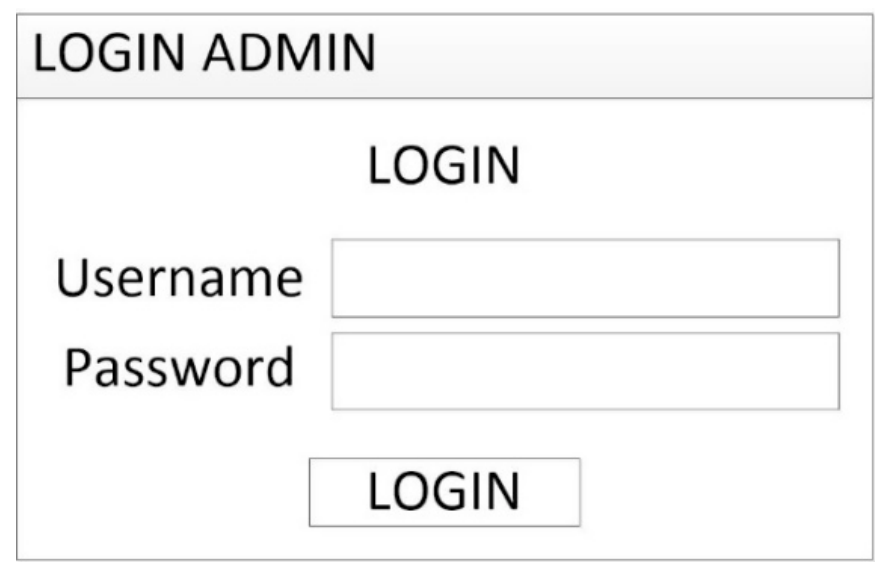

Gambar 6. Perancangan Interface Halaman Login

Sumber : Prototype Sistem Parkir dengan Internet of Things. 2016

Halaman monitor terdapat pada halaman monitor yang ditujukan untuk admin. Halaman ini bertujuan agar pengguna dapat melihat informasi seputar kondisi parkir. 


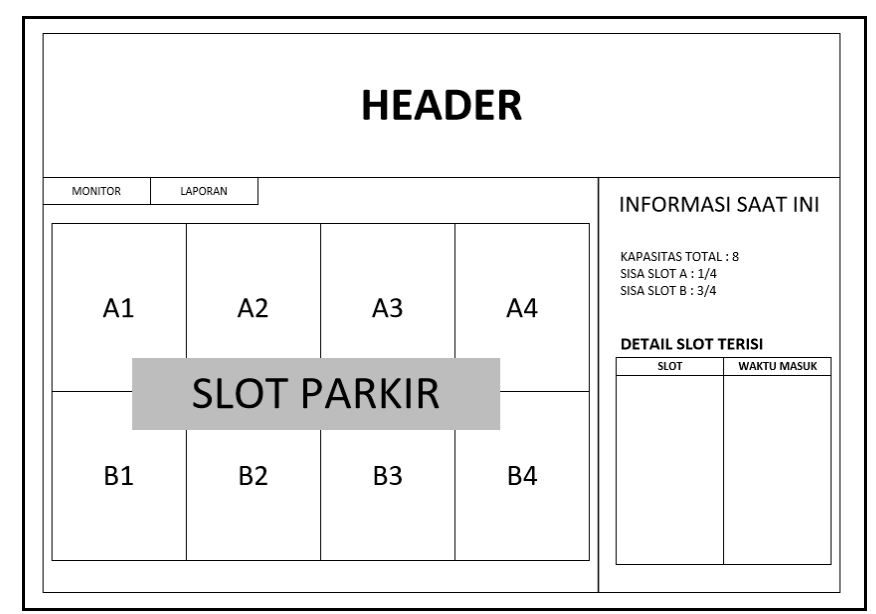

Gambar 7. Perancangan Halaman Monitor

Sumber : Prototype Sistem Parkir dengan Internet of Things. 2016

Halaman laporan terdapat pada halaman laporan yang ditujukan untuk admin. Halaman ini bertujuan agar pengguna dapat melihat laporan seputar informasi parkir yang diinginkan.

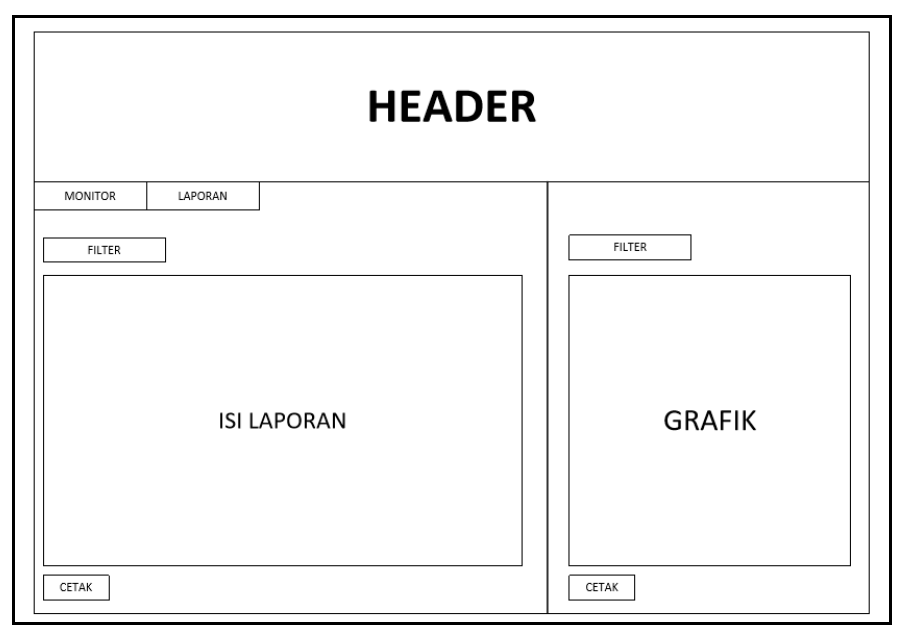

Gambar 8. Perancangan Halaman Laporan

Sumber : Prototype Sistem Parkir dengan Internet of Things. 2016

\subsubsection{Implementasi dan Pengujian Unit}

Perancangan sistem yang dihasilkan akan diimplementasikan menjadi sebuah prototype sistem parkir. Prototype diimplementasikan menggunakan Intel Galileo Board Gen 2, sensor LDR (Light Dependent Resistor) dan sensor ultrasonik (PING) yang terintegrasi dengan database MySQL. 


\subsubsection{Integrasi dan Pengujian Sistem}

Untuk melihat hasil dari aplikasi yang telah dibuat, dilakukan tahap uji coba. Metode uji yang digunakan sama dengan metode yang digunakan saat pengujian unit, yaitu blackbox. Menurut Indriasari[4], metode Pengujian Black Box adalah metode pengujian yang menguji fungsionalitas sistem. Metode tersebut dilakukan untuk memastikan apakah fungsi berjalan dengan benar jika diberikan masukan yang bervariasi. Hal ini dimaksudkan untuk melihat apakah sistem yang berjalan sudah berjalan dengan baik atau ada kesalahan pada program. Apabila ada kesalahan pada program akan diperbaiki kembali sampai hasil sesuai dengan yang diharapkan.

\section{HASIL DAN PEMBAHASAN}

\subsection{Hasil}

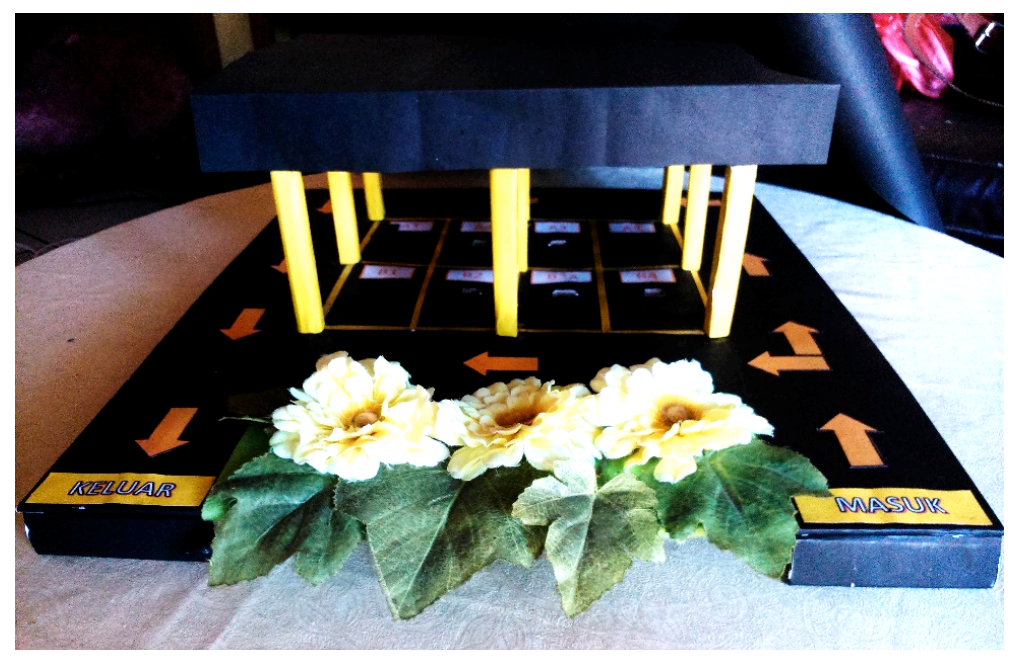

Gambar 9. Maket Lahan Parkir

Sumber : Prototype Sistem Parkir dengan Internet of Things. 2016

Maket lahan parkir diatas terdiri dari pondasi, lantai dasar, tiang penyangga, atap tengah dan atap atas. Pondasi dibuat untuk menjadi pijakan maket lahan parkir, selain itu berfungsi untuk memberikan ruang untuk penanaman sensor LDR (Light Dependent Resistor) pada bagian lantai dasar. Tiang penyangga dibuat untuk menyangga atap tengah yang telah ditanamkan sensor PING dan LED menghadap ke arah lantai dasar. Sedangkan atap atas berfungsi sebagai tempat peletakan kontroler Intel Galileo Gen 2, selain itu atap atas juga berfungsi untuk menutup bagian atas maket sehingga maket akan terlihat lebih rapi.

Berikut akan ditampilkan implementasi dari perancangan User Interface yang telah dibuat sebelumnya:

a. Halaman Login

Pada form ini admin (pengelola parkir) melakukan login dengan memasukkan username dan password. Kemudian sistem akan melakukan validasi. Saat admin memasukan data yang benar, maka user akan masuk ke Form berikutnya, 
Sedangkan apabila data admin yang di masukan salah maka akan muncul pesan kesalahan bahwa password yang dimasukkan salah.

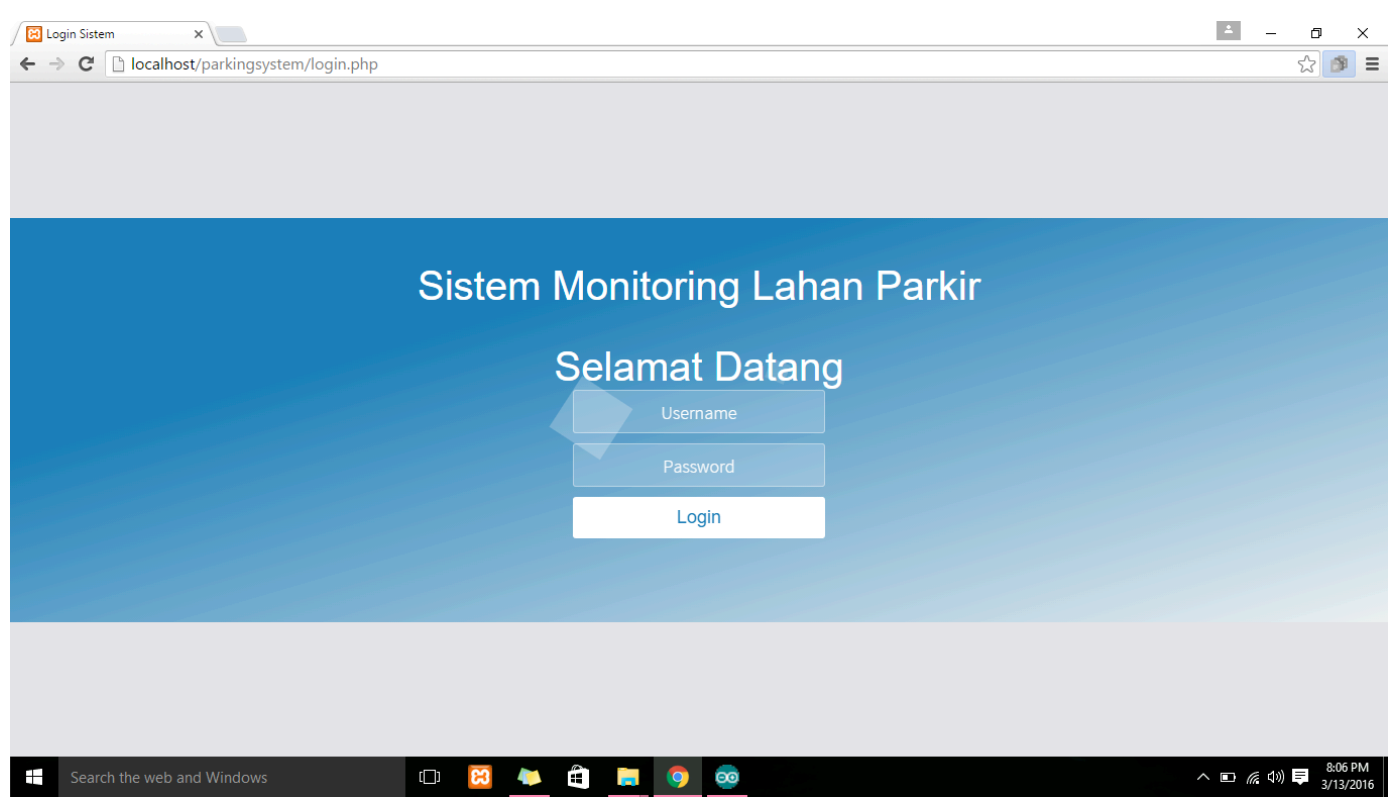

Gambar 10. Halaman Login

Sumber : Prototype Sistem Parkir dengan Internet of Things. 2016

b. Halaman Monitor

Halaman ini digunakan oleh pengelola parkir untuk mengetahui informasi mengenai aktifitas lahan parkir dan membantu pengelola dalam melakukan monitoring kondisi lahan parkir.

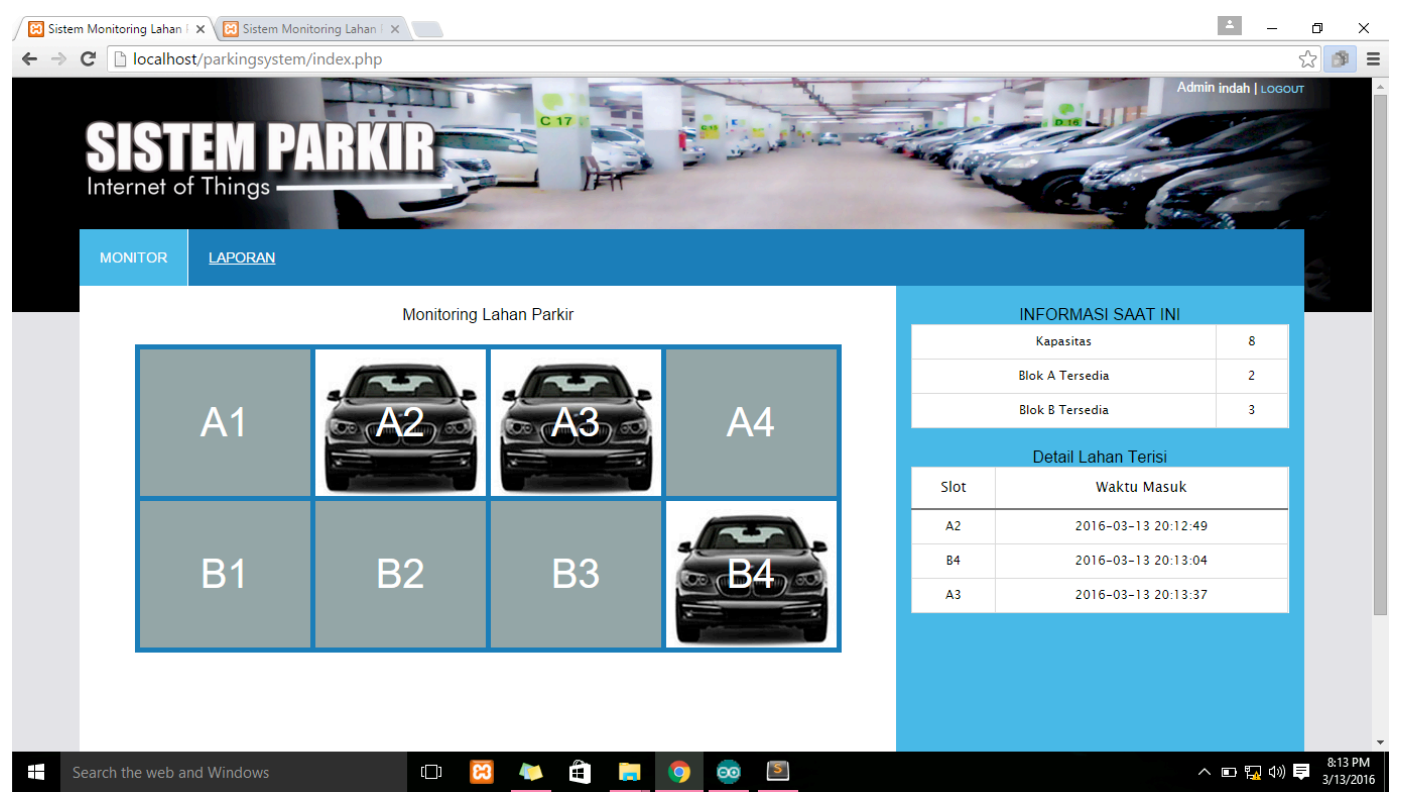

Gambar 11. Halaman Monitor

Sumber : Prototype Sistem Parkir dengan Internet of Things. 2016 
c. Halaman Laporan

Halaman laporan merupakan halaman yang digunakan oleh pengelola parkir untuk melihat, memfilter dan mencetak laporan aktifitas parkir. Selain itu pada halaman ini pengelola parkir juga dapat melihat grafik aktifitas parkir. Serta melakukan aksi filter dan cetak terhadap laporan yang ada.

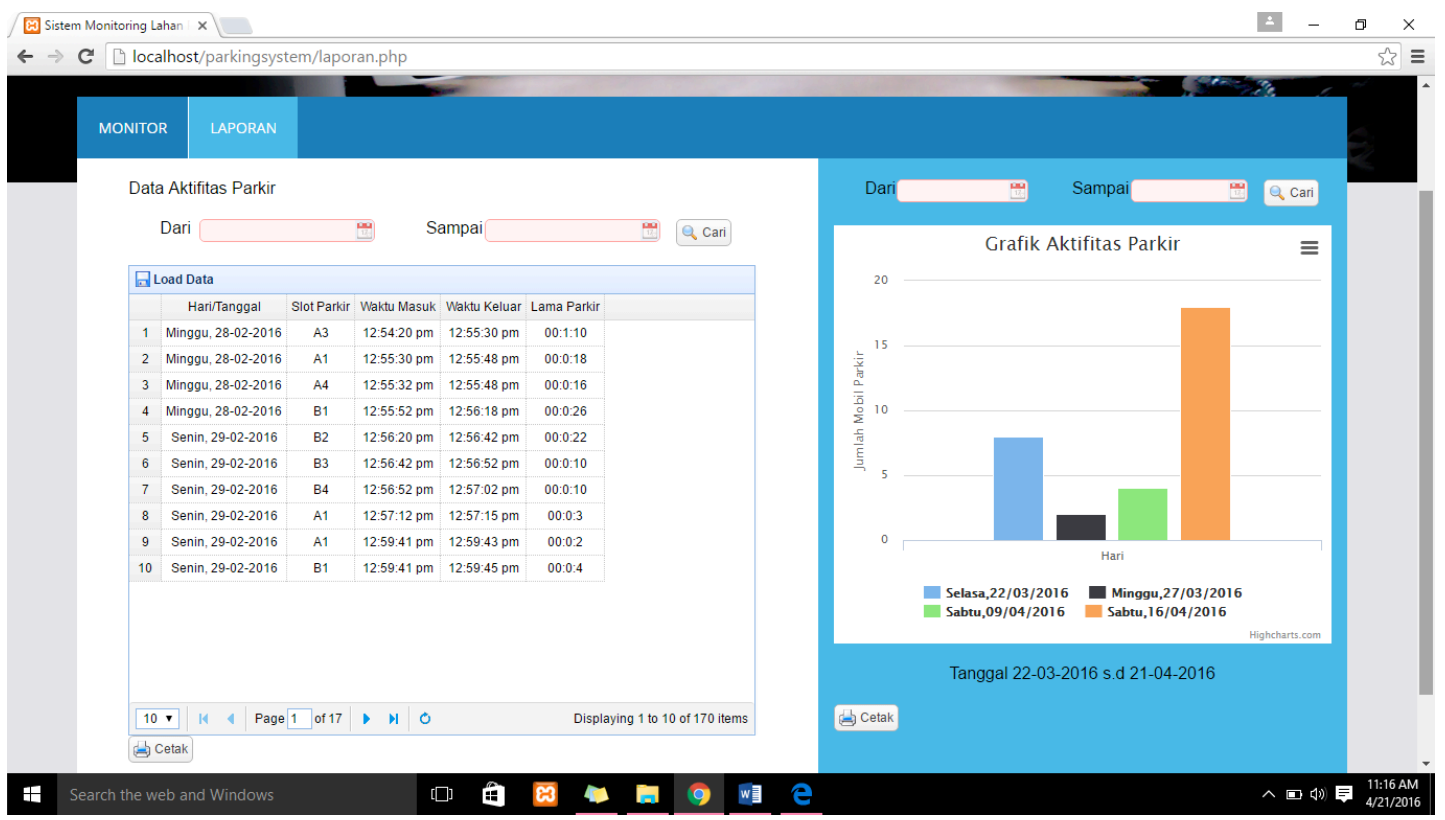

Gambar 12. Halaman Laporan

Sumber : Prototype Sistem Parkir dengan Internet of Things. 2016

\subsection{Pembahasan}

Pembahasan diperlukan untuk mengetahui apakah hasil dari penelitian ini sudah dapat menyelesaikan permasalahan yang ada. Maket diimplementasikan untuk mengetahui gambaran sistem secara keseluruhan. Maket lahan parkir terdiri dari satu lantai dengan jumlah total delapan slot lahan parkir yang dibagi menjadi dua blok, yaitu blok A dan B.

Penelitian ini menggunakan dua buah jenis sensor yang berbeda yaitu sensor LDR (Light Dependent Resistor) dan sensor ultrasonik. Pada sistem ini ditambahkan LED (Light Emitting Diode) yang dihadapkan dengan LDR sehingga dapat dikategorikan sebagai "terang" (kondisi lahan parkir kosong) dan jika lahan parkir terisi (mobil menutupi sensor LDR) maka dapat dikategorikan sebagai "gelap". Sensor ultrasonik memanfaatkan pancaran gelombang ultrasonik yang memantul ke objek untuk kemudian diterima dan diolah menjadi data. Data inilah yang akan digunakan sebagai acuan penentuan kondisi parkir terisi/kosong pada website.

Pengujian sistem terhadap maket dilakukan untuk mengetahui apakah sistem dapat diterapkan dengan baik pada maket dan dapat memberikan hasil yang sesuai. Pengujian dilakukan dengan pembacaan sensor dalam kondisi lahan parkir kosong dan lahan parkir dalam kondisi terisi. Jika sensor mendeteksi keberadaan mobil maka informasi keberadaan mobil (lahan parkir terisi) akan ditampilkan pada aplikasi web beserta dengan informasi pendukung seperti waktu 
masuk dan jumlah kapasitas lahan parkir yang tersedia. Begitu juga saat kondisi lahan parkir kosong, maka pada aplikasi web dapat dilihat kondisi lahan parkir yang kosong dan kapasitas parkir yang masih tersedia.

Tabel 1. Hasil Pengujian Maket

\begin{tabular}{cccc}
\hline Slot & Sensor & Kondisi Kosong & Kondisi Terisi \\
\hline A1 & PING 1 & Sukses & Sukses \\
A2 & LDR 1 & Sukses & Sukses \\
A3 & LDR 2 & Sukses & Sukses \\
A4 & PING 2 & Sukses & Sukses \\
B1 & PING 3 & Sukses & Sukses \\
B2 & LDR 3 & Sukses & Sukses \\
B3 & LDR 4 & Sukses & Sukses \\
B4 & LDR 5 & Sukses & Sukses \\
\hline
\end{tabular}

Sumber : Prototype Sistem Parkir dengan Internet of Things. 2016

\section{SIMPULAN}

Dari hasil penelitian dan pengamatan dari sistem yang telah dibuat, maka dapat diperoleh kesimpulan bahwa perancangan dan pengembangan sistem berhasil diimplementasikan. Sehingga pengelola parkir dapat mendapatkan informasi aktifitas parkir yang bermanfaat untuk memonitoring kondisi lahan parkir dilapangan dan pengelolaan informasi yang bisa digunakan dalam pengembangan sistem parkir lebih lanjut.

\section{DAFTAR PUSTAKA}

[1] Septriyaningrum, Indah Ayu. 2016. Prototype Sistem Parkir dengan Internet of Things. Skripsi Ilmu Komputer, Universitas Lambung Mangkurat.

[2] Imbiri, Freeon Alkapon. 2016. Implementasi Sistem Perparkiran Otomatis dengan Menentukan Posisi Parkir Berbasis RFId vol 4, No.1, hal 31-46. Teknik Elektro, Bandung.

[3] Laudon, Kenneth C, Jane P. Laudon. 2008. Sistem Informasi Manajemen Edisi 10. Salemba Empat, Jakarta.

[4] Indriasari, Sofiyanti. 2012. Sistem Informasi Berbasis Web Untuk Membantu Kegiatan Tracer Study Program Diploma Institut Pertanian Bogor vol 2, No.1, hal 84-102.

[5] Presman, Roger S. 2002. Rekayasa Perangkat Lunak : Pendekatan Praktisi (Buku Satu). Yogyakarta : Andi dan McGraw-Hill Book Co.

[6] Kusnendar, Jajang. 2009. Perangkat Lunak Untuk Mentransformasikan Model Entity Relationship Ke Model Reational. Vol. 2, No.2. Universitas Pendidikan Indonesia. 